\title{
CANCER
}

\section{Effect of faecal occult blood screening on mortality from colorectal cancer: results from a randomised controlled trial}

\author{
J H Scholefield, S Moss, F Sufi, C M Mangham, J D Hardcastle
}

See end of article for authors' affiliations .......................

Correspondence to: Professor J H Scholefield, Division of GI Surgery, University Hospital,

Nottingham NG72 UH, UK; john.scholefield@ nottingham.ac.uk

Accepted for publication 17 July 2001

\begin{abstract}
Background: Three large randomised trials have shown that screening for colorectal cancer using faecal occult blood (FOB) tests can reduce the mortality from this disease. Two national pilot studies have recently been launched in the UK to investigate the feasibility of population screening for colorectal cancer in the National Health Service. The largest of the randomised trials was conducted in Nottingham and randomised 152850 individuals between the ages of 45 and 74 years to receive biennial Haemoccult (FOB) test kit (intervention group) or to a control group.

Aims: We have compared the mortality in the intervention group compared with the control group.

Methods: The 152850 randomised individuals were followed up through local health records and central flagging (Office for National Statistics) over a median follow up period of 11 years.

Results: At a median follow up of 11 years there was a 13\% reduction in colorectal cancer mortality $195 \%$ confidence interval 3-22\%) in the intervention group despite an uptake at first invitation of only approximately $50 \%$. The mortality reduction for those accepting screening was $27 \%$. The reduction in mortality was independent of sex and site of tumour. There was no significant difference in mortality from causes other than colorectal cancer between the intervention and control groups.

Conclusions: Although the reduction in colorectal cancer mortality was sustained, further follow up of this population is required to determine whether a significant reduction in the incidence of colorectal cancer will be achieved.
\end{abstract}

\section{METHODS}

Between February 1981 and January 1991, 152850 subjects aged 45-74 years living in the Nottingham area were randomly allocated to an intervention or control group and the intervention group was offered two yearly screening by FOB testing. Randomisation was by household but over half the subjects were in single person households. Controls were not told about the study and received no intervention. The methodology of the trial is described in more detail elsewhere. ${ }^{72}$ It is now nine years since the last subjects were enrolled and five years since screening ceased; median follow up is now 11 (range 8-18) years. The whole population has been followed up through local hospital records and flagging at the NHS central register (Office for National Statistics (ONS)) to determine subsequent incidence of CRC and mortality from all causes.

Structured case note reviews of certified and registered CRC cases were carried out in order to obtain more reliable information on cause of death. CRC mortality rates were calculated from both the underlying cause of death as stated on the death certificate and the verified cause of death obtained after review of the case notes. The verification process was blind to intervention or control group except in approximately $5 \%$ of deaths reviewed (59 of 1277 deaths) where it was evident from the case notes that the patient had been in the screened group.

Person years in the intervention and control groups were calculated from date of study entry to 30 June 1999 or death, whichever was earlier. The date of entry for all participants in the study was taken to be the date on which the first invitations for screening were sent to intervention group participants in their particular general practice. For all deaths from CRC in either group, date of diagnosis was determined from hospital records or ONS cancer registrations. All deaths attributable to CRC when the diagnosis of CRC had been made before the date of study entry were excluded.

Cumulative mortality and incidence rates were calculated by dividing the total number of deaths from, or cases of, CRC by the total number of subjects randomised to that group, at each year since randomisation. However, the plots of these

Abbreviations: CRC, colorectal cancer; $F O B$, faecal occult blood; RR relative risk; ONS, Office for National Statistics. 
Table 1 Colorectal cancer (CRC) incidence, mortality rates, and mortality ratios in the intervention and control groups

\begin{tabular}{|c|c|c|c|c|c|}
\hline & \multirow[b]{2}{*}{ Intervention group } & \multirow[b]{2}{*}{ Control group } & \multicolumn{2}{|c|}{ Rate (per 1000 person years) } & \multirow[b]{2}{*}{ Rate ratio $(95 \% \mathrm{Cl})$} \\
\hline & & & Intervention group & Control group & \\
\hline No recruited & 76224 & 76079 & & & \\
\hline Person years & 844419 & 843463 & & & \\
\hline CRC cases & 1268 & 1283 & 1.51 & 1.53 & $\begin{array}{l}0.99(0.91-1.07, p=0.74) \\
0.99(0.92-1.07, p=0.79)\end{array}$ \\
\hline Deaths from verified CRC & 593 & 684 & 0.70 & 0.81 & $\begin{array}{l}0.87(0.78-0.97, p=0.01) \\
0.87(0.78-0.97, p=0.01) \text { * }\end{array}$ \\
\hline Deaths from all causes & 20421 & 20336 & 24.18 & 24.11 & $\begin{array}{l}1.00(0.98-1.02, p=0.79) \\
1.00(0.99-1.02, p=0.62) \text { * }\end{array}$ \\
\hline
\end{tabular}

${ }^{*}$ Adjusted for age and sex.

rates reflect the decreasing completeness of follow up with increasing time since randomisation. In addition therefore Nelson-Aalen estimates of cumulative mortality were calculated from the number of deaths (or cases) in each year since randomisation divided by the number of person years observed during that year and summing these individual rates. ${ }^{13}$

CRC incidence and mortality rates were calculated as the number of cases of and deaths from CRC divided by the total person years. A standard "intention to treat" analysis was performed with the control group data as the denominator to calculate estimates of relative incidence and mortality. Poisson regression, offset by the natural logarithm of person years of observation, was used to calculate incidence and mortality rate ratios relative to the control group and also to provide $95 \%$ confidence intervals for these estimates. The variation in these rate ratios with age and sex was also investigated using Poisson regression. Poisson models were compared by the likelihood ratio test. Proportions were compared using the $\chi^{2}$ test.

In the standard "intention to treat" analysis, mortality rates in the whole of the intervention group are compared with the control group. It is also possible to estimate the mortality reduction in those accepting screening, relative to the control group. However, when those accepting screening are at different underlying risk from non-acceptors of screening the standard method of analysis will underestimate or overestimate the relative risk (depending on whether non-acceptors are at higher or lower risk than the control group), and also produce confidence intervals which are too narrow. An additional method of analysis described by Cuzick and colleagues $^{14}$ allows for differences in underlying rates in the acceptors and non-acceptors of screening in order to produce a less biased estimate of relative risk (assuming that the underlying rate in acceptors is equivalent to that in the control group adjusted for the rate in the non-acceptors). The confidence intervals are also increased so that the level of significance is not greatly changed. This method has been used to provide an estimate of CRC mortality in those accepting the first screening test relative to the control group.

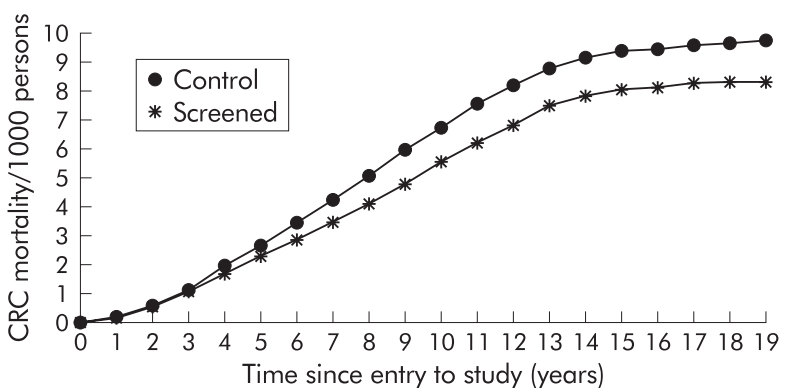

Figure 1 Cumulative incidence of colorectal cancer (CRC) in the control and screened groups.
Cause specific mortality has been investigated in subjects in the control and intervention groups, the latter subdivided according to whether they had accepted at least one test. In order to study the risk of ischaemic heart disease following a positive test/colonoscopy, mortality rates were calculated for unscreened subjects in the intervention group using deaths and person years up to the date of a first test. After a first negative test, events and person years of follow up were allocated to the "negative" category until the date of a first positive test; all subsequent follow up was included as following a positive test. In addition, mortality in the first 12 months since date of entry for those with a positive test at first invitation was compared with that in the control group.

\section{RESULTS}

Of the 152850 individuals recruited, 76466 were randomised by household to the intervention group and 76384 to the control group; $547(0.4 \%)$ could not be traced by ONS or had emigrated and were therefore excluded from the mortality analysis. Of the remaining 152303 study participants, 76224 were in the intervention group and 76079 were in the control group. Median follow up was 11.7 (range 8.4-18.4) years. The total person years of observation in each group was 844419

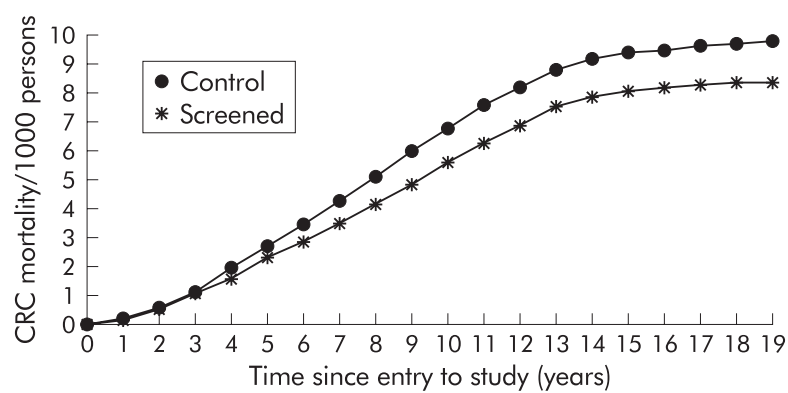

Figure 2 Cumulative mortality from verified colorectal cancer $(C R C)$ in the control and screened groups.

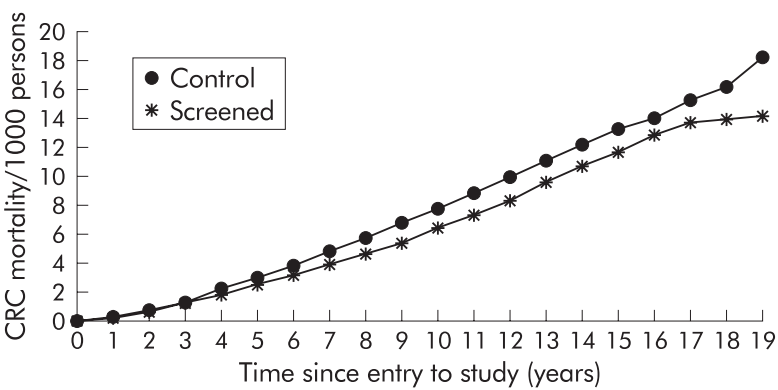

Figure 3 Nelson-Aalen estimates of cumulative mortality from colorectal cancer (CRC) in the control and screened groups. 
Table 2 Verified colorectal cancer (CRC) mortality rates by age and sex

\begin{tabular}{|c|c|c|c|c|c|}
\hline & \multicolumn{2}{|l|}{ No of deaths } & \multicolumn{2}{|c|}{ Rate (per 1000 person years) } & \multirow[b]{2}{*}{ Mortality ratio $(95 \% \mathrm{Cl})$} \\
\hline & $\begin{array}{l}\text { Intervention } \\
\text { group }\end{array}$ & $\begin{array}{l}\text { Control } \\
\text { group }\end{array}$ & $\begin{array}{l}\text { Intervention } \\
\text { group }\end{array}$ & $\begin{array}{l}\text { Control } \\
\text { group }\end{array}$ & \\
\hline \multicolumn{6}{|l|}{ Sex* } \\
\hline Females & 261 & 304 & 0.58 & 0.68 & $0.86(0.72-1.01, p=0.06)$ \\
\hline Males & 332 & 380 & 0.85 & 0.97 & $0.88(0.76-1.01, p=0.08)$ \\
\hline \multicolumn{6}{|c|}{ Age at entry $\dagger$} \\
\hline$<65 y$ & 300 & 348 & 0.50 & 0.58 & $0.86(0.74-1.00, p=0.05)$ \\
\hline$\geqslant 65 y$ & 293 & 336 & 1.20 & 1.37 & $0.88(0.75-1.02, p=0.10)$ \\
\hline
\end{tabular}

Table 3 Verified colorectal cancer (CRC) mortality rates by site of cancer*

\begin{tabular}{|c|c|c|c|c|c|}
\hline & \multicolumn{2}{|l|}{ No of deaths } & \multicolumn{2}{|c|}{ Rate (per 1000 person years) } & \multirow[b]{2}{*}{ Mortality ratio $(95 \% \mathrm{Cl})$} \\
\hline & $\begin{array}{l}\text { Intervention } \\
\text { group }\end{array}$ & $\begin{array}{l}\text { Control } \\
\text { group }\end{array}$ & $\begin{array}{l}\text { Intervention } \\
\text { group }\end{array}$ & $\begin{array}{l}\text { Control } \\
\text { group }\end{array}$ & \\
\hline \multicolumn{6}{|l|}{ Site of cancer $\dagger$} \\
\hline Proximal to the sigmoid colon & 212 & 251 & 0.25 & 0.30 & $0.84(0.70-1.01, p=0.068)$ \\
\hline Distal cancers & 368 & 420 & 0.44 & 0.50 & $0.88(0.76-1.01, p=0.062)$ \\
\hline
\end{tabular}

and 843463 , respectively. Both intervention and control groups were well matched in terms of age and sex.

Cumulative CRC incidence at the end of the follow up period was similar in the intervention group and the control group ( $1.51 \vee 1.53$ per 1000 person years; $\mathrm{p}=0.76)$ (table 1 ). Adjusting for age and sex did not alter this estimate. Figure 1 shows the cumulative incidence in the screening and control groups after 18 years of follow up. During the earlier part of the study (up to five years) the incidence of CRC was higher in the intervention group compared with the control group due to the advance in date of diagnosis by screening. This pattern was reversed at eight years after which the cumulative incidence of CRC in the control group exceeded that in the intervention group. At no point was the difference in incidence of CRC between the intervention and control groups statistically significant.

Overall, $20421(26.8 \%)$ subjects in the intervention group and $20336(26.7 \%)$ in the control group have died during the study period. The rate of verified deaths from CRC was lower in the intervention group compared with controls $(0.70 \mathrm{v}$ 0.81 ), giving a $13 \%$ reduction in mortality in the intervention group (relative risk (RR) $0.87,95 \%$ CI $0.78-0.97 ; p=0.010$ ) (table 1). Adjusting for age and sex had little effect on the estimate of CRC mortality (table 1) or on the $95 \%$ confidence interval.

Figure 2 shows the cumulative CRC mortality in the intervention and control groups for up to 18 years of follow up from study entry. Differences in CRC mortality between the intervention and control groups emerged after 3-4 years. The shape of the curve reflects the cumulative recruitment to the study over a 10 year period. As few subjects have been in the trial for longer than 10 years, the cumulative mortality rates have risen more slowly after this time. Figure 3 shows the cumulative CRC mortality in the intervention and control groups for up to 18 years of follow up from study entry using the Nelson-Aalen estimate of cumulative mortality which continues to increase after 10 years of observation. There was no significant difference between the mortality rates for verified deaths from CRC in males and females or in the different age groups (table 2 ).

There was a $16 \%$ reduction in mortality for cancer proximal to the sigmoid colon (RR 0.84 (95\% CI 0.70-1.01)), and a 12\%
Table 4 Incidence and mortality ratios in acceptors of faecal occult blood screening compared with controls (adjusted for non-acceptance of the first test)

\begin{tabular}{ll}
\hline & Rate ratio $(95 \% \mathrm{Cl})$ \\
\hline CRC & $0.98(0.83-1.13)$ \\
Deaths from verified CRC & $0.73(0.57-0.90)$ \\
Deaths from all causes & $1.01(0.96-1.05)$ \\
\hline CRC, colorectal cancer. &
\end{tabular}

reduction for distal cancers $(0.88(0.76-1.01))$ (table 3$)$. The estimated mortality reduction in those accepting the first test was $27 \%$ for verified CRC mortality relative to the control group $(0.73(0.57-0.90))$ (table 4$)$. The adjustment had a similar effect in different age and sex subgroups.

Mortality from all causes other than CRC was similar in the intervention and control groups. Among the intervention group, 1977 tested positive at least once, a cumulative risk of having a positive test of $2.6 \%$ ( 1977 of 76224 ). Of these, 1439 $(73 \%)$ underwent colonoscopy with the remainder undergoing other investigations such as barium enema. The cumulative proportion of the whole intervention group who underwent at least one colonoscopy as part of their follow up after a positive test was therefore $1.9 \%$. The decision to send some patients for barium enema was a clinical decision based on coexisting cardiovascular or respiratory disease. Cause specific mortality rates by acceptance of FOB testing have been summarised in table 5. With the exception of deaths from $\mathrm{CRC}$, there were no significant differences in the major causes of death between the intervention group and the control group. Among the intervention group, there was a significant increase in deaths from all causes in the group who were never screened compared with the group who accepted at least one screening test. This increase occurred in all of the major groups of causes; there was no difference in death rates from suicide between these two groups.

A variety of complications associated with colonoscopy have been reported, the most serious of which are cardiovascular. ${ }^{15}$ In this study overall mortality from ischaemic heart disease was similar in the intervention and control 
Table 5 Cause specific mortality rates (per 1000 person years) in the intervention and control groups by faecal occult blood testing

\begin{tabular}{|c|c|c|c|c|}
\hline \multirow[b]{2}{*}{ Person years of observation } & \multicolumn{3}{|c|}{ Intervention group } & \multirow[b]{2}{*}{$\begin{array}{l}\text { Control group } \\
\text { (843 463) }\end{array}$} \\
\hline & $\begin{array}{l}\text { Tested* } \\
\text { (478 662) }\end{array}$ & $\begin{array}{l}\text { Not tested } \dagger \\
(365 \text { 757) }\end{array}$ & $\begin{array}{l}\text { Total } \\
\text { (844 419) }\end{array}$ & \\
\hline \multicolumn{5}{|l|}{ Cause of death } \\
\hline Neoplasms (other) & $2799(5.85)$ & $2640(7.22)$ & $5439(6.44)$ & $5405(6.41)$ \\
\hline Respiratatory disease (incl. pulmonary disease) & $1164(2.43)$ & $1448(3.96)$ & $2612(3.09)$ & $2648(3.14)$ \\
\hline Digestive system disease & $265(0.55)$ & $338(0.92)$ & $603(0.71)$ & $624(0.74)$ \\
\hline Colorectal cancer & $261(0.55)$ & $297(0.81)$ & $558(0.66)$ & $626(0.74)$ \\
\hline Ischaemic heart disease & $2563(5.35)$ & $2430(6.64)$ & $4993(5.91)$ & $4956(5.88)$ \\
\hline Other heart disease & $387(0.81)$ & $429(1.17)$ & $816(0.97)$ & $760(0.90)$ \\
\hline Cerebrovascular disease & $769(1.61)$ & $867(2.37)$ & $1636(1.94)$ & $1656(1.96)$ \\
\hline Peripheral vascular disease & $740(1.55)$ & $802(2.19)$ & $1542(1.83)$ & $1471(1.74)$ \\
\hline Suicide & $35(0.07)$ & $28(0.08)$ & $63(0.07)$ & $63(0.07)$ \\
\hline All other causes & $1026(2.14)$ & $1133(3.10)$ & $2159(2.56)$ & $2127(2.57)$ \\
\hline
\end{tabular}

\begin{tabular}{|c|c|c|c|c|c|c|}
\hline \multirow[b]{3}{*}{ Person years of observation } & \multicolumn{5}{|c|}{ Intervention group } & \multirow[b]{3}{*}{$\begin{array}{l}\text { Control group } \\
(843463)\end{array}$} \\
\hline & \multirow[b]{2}{*}{$\begin{array}{l}\text { Negative* } \\
\text { (461 650) }\end{array}$} & \multicolumn{2}{|l|}{ Positive $†$} & \multirow[b]{2}{*}{$\begin{array}{l}\text { Not tested } \neq \\
(365757)\end{array}$} & \multirow[b]{2}{*}{$\begin{array}{l}\text { Total } \\
\text { (844 419) }\end{array}$} & \\
\hline & & $\begin{array}{l}\text { Colonoscopy } \\
(11939)\end{array}$ & $\begin{array}{l}\text { No colonoscopy } \\
(5073)\end{array}$ & & & \\
\hline Ischaemic heart disease & 2448 (5.3) & $76(6.4)$ & $39(7.7)$ & $2430(6.6)$ & 4993 (5.9) & 4956 (5.9) \\
\hline
\end{tabular}

groups (table 6). The rate was higher in individuals undergoing colonoscopy following a positive test (6.4 per 1000 person years) than in the control group (5.9 per 1000 person years) but this difference was not significant (RR 1.08 (95\% CI 0.851.36)) Within the first year of entry, there were five deaths from ischaemic heart disease in 548 subjects who underwent colonoscopy after a positive test. Again this was a higher rate than in the control group but the difference was not significant (RR 2.04 (95\% CI -4.83); $\mathrm{p}=0.14$ ).

\section{DISCUSSION}

The results of the Nottingham trial at a median follow up of 7.8 years showed a reduction in mortality from CRC in the intervention group of $15 \%$ (95\% CI $0.74-0.98) .{ }^{7}$ Screening in the trial stopped in February 1995 so that the present results represent the continued effect of screening to that date. This is in contrast with the trial in Fünen, Denmark where screening is continuing. ${ }^{8}$ Long term follow up of the Minnesota trial ${ }^{16}$ showed a reduction in CRC mortality in the group offered biennial screening of $21 \%$ at 18 years of follow up whereas at 13 years only a $6 \%$ reduction had been observed. Compliance in this group averaged $78 \%$ per screen.

After a median follow up of 11 years, the number of cases of $\mathrm{CRC}$ in the control and intervention groups was similar. This is a change from previous reports arising from this study although the difference of 15 cases in approximately 1300 cancers in each group is small. Detection of precancerous adenomas should eventually lead to a reduction in the incidence of CRC. Evidence of a divergence between the incidence of CRC in the intervention and control groups is beginning to emerge from the Minnesota trial. However, this was not observed until 13 years of follow up. ${ }^{17}$ In view of the prolonged follow up required to see a change in incidence, it is perhaps not surprising that in the Nottingham study the cumulative incidence in the intervention and control groups does not appear to be diverging but follow up is ongoing.

The risk ratio of death from CRC gave a 13\% reduction in the risk of dying from CRC in the intervention group. The estimated mortality reduction in acceptors of the first test was $27 \%$. Although compliance in the present study was only $57 \%$, one might speculate that compliance would be greater in a national population screening programme once screening had been shown to be effective. There was no significant influence of age or sex on mortality in this study.

A major concern for any CRC screening programme is the number of colonoscopies generated. The cumulative colonoscopy rate in the Nottingham study was $1.9 \%$ of the intervention group using a biennial screening process.. This compares with a cumulative colonoscopy rate of $38 \%$ in the Minnesota study using an annual regimen. ${ }^{6}$ As colonoscopy is expensive in terms of manpower and facilities, it is encouraging that significant mortality reduction has been achieved with a low overall colonoscopy rate.

The causes of death other than CRC were broadly similar in the test and control groups. In common with other screening studies, it is notable that the "non-responders" generally had a higher mortality for all causes than either the "acceptors" or "controls". Consideration of the introduction of population screening has led to concern over the possible disbenefits of screening in both physical and psychological terms. No colonoscopy related deaths have been observed in the Nottingham trial although complications of colonoscopy have occurred..$^{10}$ Although concerns have been expressed over the potential psychological harm caused by screening for cancer, earlier studies of the Nottingham trial population have failed to show anything other than a transitory rise in the anxiety score 
around the time of testing (M Parker, 2000, personal communication). In the present mortality analysis there was no excess of suicide in the acceptor or test groups. Although it has been suggested that there may be an excess of cardiovascular deaths following colonoscopy in screening programmes such as this, ${ }^{11} 18$ our data showed similar rates of cardiovascular deaths in the control and intervention groups. In order to examine this question more closely, the authors specifically investigated cardiovascular deaths occurring within one year of accepting the first test offered to them (the period in which most individuals would undergo a colonoscopy), and again found no suggestion of an excess.

While the data from this study continue to show a reduction in disease specific mortality from FOB screening, despite a compliance rate of only $57 \%$, it is reassuring that there was no significant excess of deaths following the screening process. Further follow up data are awaited to determine the effect of the screening process on the incidence of this disease.

\section{Authors' affiliations}

J H Scholefield, C M Mangham, J D Hardcastle, Division of GI Surgery, University Hospital, Nottingham NG7 2UH, UK

S Moss, F Sufi, Cancer Screening Evaluation Unit, Sutton, Surrey SM2 5NG, UK

\section{REFERENCES}

1 Selby JV. Screening sigmoidoscopy for colorectal cancer. Lancet 1993:341:728-9.

2 Saito J, Soma Y, Koeda J. Reduction in risk of mortality from colorectal cancer by fecal occult blood screening with immunochemical hemagglutination test. A case-control study. Int J Cancer 1995:61:465-9.

3 Wahrendorf J, Robra BP, Wiebelt H. Effectiveness of colorectal cancer screening: results from a population-based case-control evaluation in Saarland, Germany. Eur J Cancer Prev 1993;2:221-7.
4 Lazovich DA, Weiss NS, Stevens NG. A case-control study to evaluate efficacy of screening faecal occult blood. J Med Screen 1995;2:84-9.

5 Zappa M, Castiglione G, Grazzini G. Effect of faecal occult blood testing on colorectal cancer mortality: results of a population-based case-control study in the district of Florence, Italy. Int J Cancer 1997;73:208-10

6 Mandel JS, Bond JH, Church TR. Reducing mortality from colorectal cancer by screening for fecal occult blood. N Engl J Med 1993:328:1365-71.

7 Hardcastle JD, Chamberlain JO, Robinson MHE. Randomised controlled trial of faecal occult blood screening for colorectal cancer. Lancet 1996;348: 1472-7.

8 Kronborg O, Fenger C, Olsen J. Randomised study of screening for colorectal cancer with faecal-occult-blood test. Lancet 1996;348:146771.

9 Towler B, Irwig L, Glasziou P. A systematic review of the effects of screening for colorectal cancer using the faecal occult blood test Haemoccult. BM 1998;317:559-65.

10 Robinson $M$, Hardcastle J, Moss S, et al. The risks of screening: data from the Nottingham randomised controlled trial of faecal occult blood screening for colorectal cancer. Gut 1999;45:588-92.

11 Atkin W. Screening for colorectal cancer: the heart of the matter. Gut 1999:45:480-1

12 Hardcastle JD, Thomas WM, Chamberlain J, et al. Randomised controlled trial of faecal-occult-blood screening for colorectal cancer; the results of the first 107,349 subjects. Lancet 1989;i: 1160-4.

13 Breslow NE, Day NE. Statistical methods in cancer research, vol. 1: The analysis of case control studies. Lyon: International Agency for Research on Cancer, 1980

14 Cuzick J, Edwards R, Segnan N. Adjusting for non-compliance and contamination in randomised clinical trials. Stat Med 1997;16:101729.

15 Atkin WS, Hart A, Edwards R. Uptake, yield of neoplasia, and adverse effects of flexible sigmoidoscopy screening. Gut 1998;42:560-5.

16 Mandel JS, Church TR, Ederer F, et al. Colorectal cancer mortality: Effectiveness of biennial screening for fecal occult blood. J Natl Cancer Inst 1999:91:434-7.

17 Mandel JS, Church TR, Bond JH, et al The effect of fecal occult blood screening on the incidence of colorectal cancer. N Engl J Med 2000:343: 1603-7.

18 Ahlquist DA. Fecal occult blood testing for colorectal cancer-can we afford to do this. Gastroenterol Clin North Am 1997;26:41-55. 